Philadelphia: WB Saunders, 1984:769-870.

15 Dyck PJ, Lais AC, Michiya O, Bastron JA, Harud O, Groover RV. Chronic inflammatory polyradiculoneuropathy. ver RV. Chronic inflammatory

16 McCombe PA, Pollard JD, McLeod JG. Chronic inflammatory demyelinating polyradiculoneuropathy. A clinical and electrophysiological study of 92 cases. Brain 1987;110: $1617-30$.
17 Barohn RJ, Kissel JT, Warmolts JR, Mendell JR. Chronic inflammatory demyelinating polyradiculoneuropathy. inflammatory demyelinating polyradiculoneuropathy. diagnostic criteria. Arch Neurol 1989;46:878-84.

18 Notermans NC, Wokke JHJ, Franssen H, et al. Chronic idiopathic polyneuropathy presenting in middle or old age: a clinical and electrophysiological study of 75 patients. f Neurol Neurosurg Psychiatry 1993;56:1066-71.

\title{
NEUROLOGICAL STAMP
}

\section{Charles Edouard Brown-Séquard (1818-94)}

Brown-Séquard, the son of an American sea captain and a French woman, was born on the island of Mauritius. Mauritius had formerly been French but it was British at the time of Brown-Séquard's birth, making him a British subject. He practised at varying times in Paris, Mauritius, London, and New York. He remained longer (four and a half years) at The National Hospital in London of which he was a founder physician, than at any other place or in any other post until 14 years later when he succeeded Claude Bernard in his final appointment as Professor of Medicine at the College de France. He took his medical degree in Paris in 1846 with a thesis on the study of reflex movements and the functions of the columns of the spinal cord.

Brown-Séquard is largely remembered for his work on the spinal cord, which culminated in his classic rendition of the symptoms manifest by hemisection of the cord (1850, 1851). After his initial studies he continued to investigate the mode and site of conduction of motor and sensory impulses in the spinal cord and together with Türck laid the foundation of the anatomy and function of the spinal cord. Brown-Séquard's second important contribution to neurology comprised studies on sympathetic control of the vasomotor mechanisms. In 1852 he gave a series of lectures in Philadelphia in which he described contraction of the blood vessels of the face after galvanic stimulation of the cervical sympathetic nerves. This discovery proved embarrassing to Claude Bernard, who later reported the same discovery and misinterpreted the findings, unaware of Brown-Séquard's work. A series of experiments (published 1856) demonstrated the connection between the excision of the adrenal glands and Addison's disease. It is for this work that he is probably best known.

In his studies of epilepsy (1856) he sought the cause and treatment for the disease and, in so doing, was among the first to advocate bromides in the treatment of epilepsy. By the 1860s Brown-Sequard was recognised as an authority and expert on all diseases of the nervous system. He continued experimenting until the end of his 77 th year. During his tenure of the Professorship at the College de France, he investigated the possibility of prolonging human life by the use of extracts prepared from the testes of different animals. This led to many abuses, the commercialisation of the products, and much unfavourable publicity. Brown-Séquard became convinced from his imperfect experiments that not only the thyroid but also the adrenal, pancreas, liver, spleen and kidneys had internal secretions that could be employed in the treatment of disease. The term internal secretions was not his own but the creation of Claude Bernard, but Brown-Séquard's work gave great stimulus to the continuing studies.

He was honoured philatelically by Mauritius, the country of his birth, on the centenary of his death in 1994 (Stanley Gibbons 903, Scott 786). 